\title{
The Cultural and Creative Product Design Based on the Taoistic Culture of Changchun Taoist Abbey
}

\author{
Hong Peng \\ Art and Design College, Wuhan University of Science and \\ Technology \\ Wuhan, Hubei \\ 395155952@qq.com
}

\author{
Zhengyang $\mathrm{Li}$ \\ Art and Design College, Wuhan University of Science and \\ Technology \\ Wuhan, Hubei \\ 252768366@qq.com
}

\author{
Zhiqiang Liu \\ Art and Design College, Wuhan University of Science and Technology \\ Wuhan, Hubei \\ 395155952@qq.com
}

\begin{abstract}
With the increasing diversity of spiritual and cultural needs of society in today's society, more and more cultural symbols in traditional culture have been excavated by people. Through the organic combination with modern products, they are endowed with modern cultural and creative products and new cultural values. The thesis will further excavate and sum up its unique cultural symbols through literature research of Wuhan Changchun Taoist Temple Taoism culture. Finally, the thesis will through the cultural and creative product design examples, summing up spiritual and cultural needs which adapt to modern social life, put forward a set of widely creative product design method, and accelerate the Taoism culture in modern life diversified communication.
\end{abstract}

Keywords-Changchun Taoistic Abbey; Taoistic culture; The design methods of cultural and creative product; Cultural and creative product

\section{INTRODUCTION}

Now the designs with local cultural characteristics are popular among people. The local cultural element is viewed, thought about and defined again by the design community to produce products which are more satisfying for the cultural and aesthetic needs of guests [1]. Taoism has great influences as a traditional domestic religion. In the middle area Wuhan, the Taoistic culture of Changchun Taoistic Abbey is the most representative. According to the research of the writers of the article, however, there is few cultural and creative products about Changchun Taoistic Abbey in market and the Taoistic abbey does not work hard to promote the popularity of the products. Based on the Taoistic culture of Changchun Taoistic Abbey, the article refines and designs several kinds of cultural and creative products, explores and concludes the various elements of the Taoistic Culture of Changchun Taoistic Abbey, makes the links between traditional cultural qualities and modern spiritual needs stronger and tighter, and modernizes and diversifies traditional religion images which has propagate significance.

\section{The Featured Resources AND TAOISM OF ChangChun TaOistic ABBeY}

Changchun Taoistic Abbey in Wuhan has a long history and was once destroyed because of war, then was rebuilt in 1863. It is the largest and the most well-kept ancient architectural complex of Taoism [2]. The Taoistic abbey is famous for its four great things: the only celestial map in China, the buildings in Tibetan and European styles, Gantang stone inscription given by Qianlong emperor and Taoistic rhymes study. The colors, items and languages are representative for expressing the spiritual meanings of Taoism.

In the letter To Xu Shouchang by $\mathrm{Lu}$ Xun, there were sayings that "the root of Chinese culture is in Taoism" [3]. Qing Xitai believed that Taoism was the product of Chinese social and historical developments, was a large and complicated system led by "Tao" [4]. They represent that Taoism and Chinese historical development are closely connected and Taoistic culture has important position in traditional Chinese culture. Taoistic culture can be divided into the following aspects despite of its complexity:

(1) Theology: Made up of Taoistic gods belief and with independent theoretical system. Has absorbed some gods and goddess from other religions as time went by, and gradually formed a perfect and large Taoistic theological system through series of cultural activities.

(2) Philosophy: Gradually formed the religion notions with "Tao" and "Morality" as center since the foundation of Taoism. The notions are almost in all the aspects of the belief, selfcultivation and the social life of the Taoists, and has formed a whole theoretical system [5].

(3) Medical Science: With the proceeding perfection of Taoistic theoretical system, some methods were taken as ways and knowledge to have longer life. Through a long period of practices there formed kinds of medical experiences. And part of them were gradually used in health maintenance because of 
their guiding effects in keeping health. (4)Culture and Art: The cultural and art works with propagating Taoism as the goal and expressing through reflecting the routines of Taoism. The textures, architectures and music derived from Taoistic culture all have their unique values. The implements with Taoistic gods belief as the root, manners, notions, and cultural and art works are countless, from which we can see the deep influence of Taostic culture on art and culture.

In conclusion, as a rather well-protected Taoistic culture base in Wuhan area, Changchun Taoistic Abbey not only contains rich Taoistic cultural relics but also has formed unique Taoism cultural scenes, brings adequate material storage for Taoistic cultural and creative product design. These outstanding culture relics are now the representative part of Changchun Taoistic Abbey after inheritance and accumulation. They should not only stay in the walls of the Taoistic abbey, also need to be selectively reflected in society and be adapt modern life. The process should be with symbolic, art and practical attributes rather than applied mechanically or taken out of context.

\section{The CurRent Situation OF TAOISTIC CUltural AND CREATIVE Products OF CHANGCHUN TAOISTIC ABBEY}

Today, although the cultural and creative products of Changchun Taoistic research in the field of literature study is less. Through field research we find out that most present cultural and creative products are traditional Taoism supplies art crafts (Figure 1). Although there are some tentative designs about Taoism elements, usually shown as promoted qualities, the combination is stiff and lack of cultural characteristics.

(1) From the aspect of appearance, they are just simple combinations of eight trigrams, calabashes and charms of Taoism, or traditional Taoism supplies such as Token with five ray backlash and red belt praying for good luck.

(2) From the aspect of meaning, they are still the material derivation of driving out evil spirits and praying for good luck in Taoism. The products are not greatly different what they were like in ancient times and the distance between them and modern life are larger and larger.

(3) From the aspect of material, most products are made of wood or metal as they are just copies of traditional Taoism supplies. Lately there are some artificial material like crystal absorbed into the production.

(4) From the aspect of skills and techniques, there are mainly traditional carving skills and the metal part are made through electroplate technology.

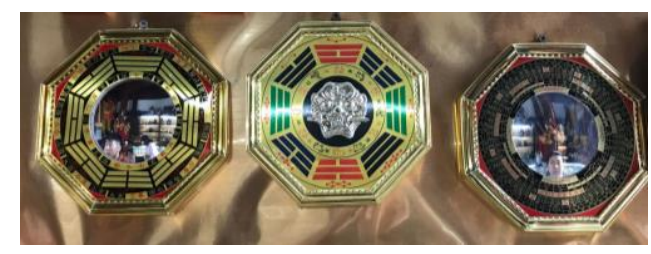

Fig. 1. The products in souvenir shops around Changchun Taoistic Abbey, Wuhan
It can be figured out from the analysis of the current cultural and creative products of Changchun that Taoistic culture has experienced development of some degree but still remains in the stage of simply copying. The Taoism characteristics are not obvious enough. The cultural and creative products are the carriers of culture and are influenced and restricted by certain culture [6], but there is also the need to obey the inside requirements of the cultural industrial development and to think and design from its economic and cultural attributes [7].

\section{THE EXPLORATION AND CONCLUSION OF THE OUTSTANDING Cultural Elements IN TAOISTIC CUlture OF CHANGCHUN TAOISTIC ABBEY}

During the process of Taoism brought the society a lot of religion culture and spiritual ballast, there appeared various of beautiful textures and special supplies which can be used as representatives in Cultural and creative design. Through combining these Taoistic textures a products, Taoistic culture are filled with new energy and directions with both aesthetic value and practical use. In modern social life of quick pace and fast technology developments, the products with metaphor meaning of Taoism provide people with spiritual ballast.

Today, when countries all over the world are exploring their cultural and creative resources, we can try to learn ways of breakthrough in examples of excellent cultural ad creative products and them combine them with Taoistic culture to produce the original products of Changchun Taoistic Abbey. There are many things we can learn from British Museum whose cultural and creative product design methods are digging the certain culture in depth while let out in directions, taking Ukiyoe and Egyptian elements as themes and derive different series of cultural and creative products in (Figure 2) are the Ukiyoe theme products. That leads them have their own way of cultural and creative production.
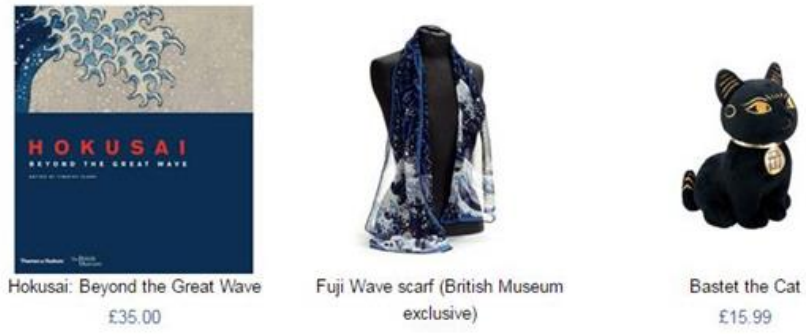

Fig. 2. The cultural and creative products page of British Museum

According to the detailed characteristics of Taoistic culture, through analyzing the design methods of British Museum, and in addition the Taoism phenomenon of Changchun Taoistic Abbey after years of developing, we try to produce some cultural and creative products that can be connected with some goods in life approachable plans. See it in Table 1. 
TABLE I. THE INNOVATION SCHEME OF THE FEASIBILITY OF THE CULTURAL AND CREATIVE PRODUCTS

\begin{tabular}{|c|c|c|c|c|c|c|c|c|c|}
\hline $\begin{array}{c}\text { Taoistic } \\
\text { Cultural } \\
\text { Representativ } \\
\text { es }\end{array}$ & \multicolumn{3}{|c|}{ Colors } & \multicolumn{3}{|c|}{$\begin{array}{c}\text { Philosophical } \\
\text { Notions }\end{array}$} & \multicolumn{3}{|c|}{$\begin{array}{l}\text { Special Areas } \\
\text { of Changchun } \\
\text { Taoistic } \\
\text { Abbey } \\
\end{array}$} \\
\hline $\begin{array}{c}\text { Detailed } \\
\text { Examples }\end{array}$ & \multicolumn{3}{|c|}{$\begin{array}{l}\text { Purple } \\
\text { Red } \\
\text { Yellow } \\
\text { Black }\end{array}$} & \multicolumn{3}{|c|}{$\begin{array}{c}\text { Keep the } \\
\text { vigour } \\
\text { Govern by } \\
\text { doing nothing } \\
\text { that against the } \\
\text { nature } \\
\text { Bamboo- } \\
\text { empty inside } \\
\text { and flexible }\end{array}$} & \multicolumn{3}{|c|}{\begin{tabular}{|c} 
Celestial map \\
Huixian \\
Bridge \\
Daozang \\
Building \\
Gantang stone \\
inscription
\end{tabular}} \\
\hline $\begin{array}{c}\text { Cases of } \\
\text { Approachable } \\
\text { cultural and } \\
\text { Creative } \\
\text { Designs }\end{array}$ & 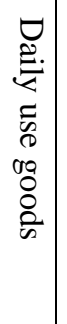 & 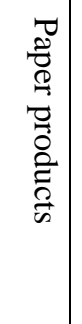 & 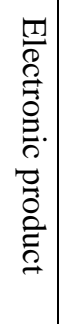 & 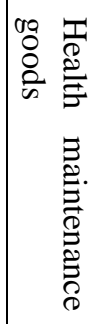 & 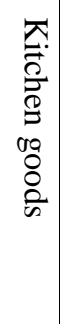 & 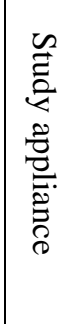 & 离. & 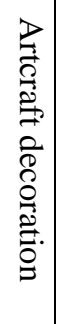 & $\begin{array}{l}\frac{\pi}{0} \\
0 \\
\stackrel{0}{0} \\
\stackrel{0}{0} \\
0 \\
0 \\
0 \\
0 \\
0\end{array}$ \\
\hline $\begin{array}{c}\text { Taoistic } \\
\text { Cultural } \\
\text { Representativ } \\
\text { es }\end{array}$ & \multicolumn{3}{|c|}{ Animals } & \multicolumn{3}{|c|}{ Implements } & \multicolumn{3}{|c|}{ Textures } \\
\hline $\begin{array}{c}\text { Detailed } \\
\text { Examples }\end{array}$ & \multicolumn{3}{|c|}{$\begin{array}{l}\text { Dragon } \\
\text { Crane } \\
\text { Deer } \\
\text { Black ox }\end{array}$} & \multicolumn{3}{|c|}{\begin{tabular}{c|} 
Token with \\
five ray \\
backlash \\
Clothes \\
The eight \\
trigrams \\
mirror \\
Peach wood \\
sword \\
\end{tabular}} & \multicolumn{3}{|c|}{\begin{tabular}{|c} 
Light trigrams \\
Tai Chi \\
Charm textures \\
The hidden \\
eight treasures
\end{tabular}} \\
\hline $\begin{array}{c}\text { Cases of } \\
\text { Approachable } \\
\text { cultural and } \\
\text { Creative } \\
\text { Designs }\end{array}$ & 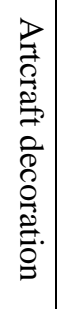 & 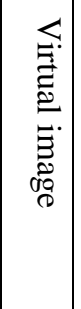 & 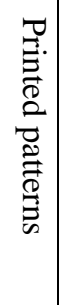 & 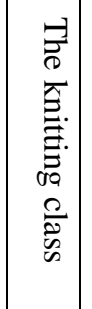 & 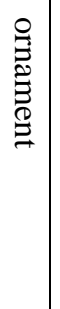 & 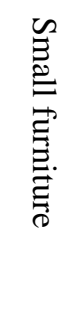 & 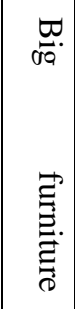 & 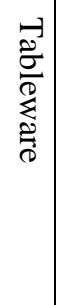 & 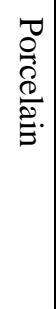 \\
\hline
\end{tabular}

To explore, conclude outstanding cultural elements in Taoistic Culture of Changchun Taoistic Abbey and match them with specific products with the plans in Table 1, the creativeness of the products including: First, to provide the application of Taoistic culture with clear and suitable derivative directions; second, Taoistic cultural and creative product design in a detailed small scale is more easy to be delicate and interesting and offers better cultural feelings to guests; third, the table generally contains the main Taoistic culture varies of Changchun Taoistic Abbey while the table can be adapted to fit the present environment of Taoistic cultural and creative product design according to the changes of times, extract the outstanding cultural elements in Taoistic culture of Changchun Taoistic Abbey more effectively.

\section{The Cases of Cultural and Creative Product Design OF CHANGCHUN TAOISTIC ABBEY}

\section{A. The Cultural and Creative Product Design with Taoistic Texture}

The formation of the Eight Diagrams is said to have been originally created by $\mathrm{Fu} \mathrm{Xi}$ in Tianshui Guatai Mountain. The Eight Diagrams represent the changing system of all things in nature, take "-" as the representative of Yang, and the "- -" as the Yin. Based on these two symbols, the Eight Diagrams form eight different arrangement styles by natural elements. The Eight Diagrams are not only the most representative symbols of Taoist culture in the public mind, but also the core elements of Taoism culture whose implication is constantly changing and comprehending all nature. By the implied meaning of the Eight Diagrams, combine this element with the currently universal mobile hard disk, a mobile hard disk which are capable of being freely assembled can be designed. (Figure 3) The main storage module is black plastic cuboid with images of elements for the appearance of the Eight Diagrams, and the silver metal wire drawing hard disk box plays the role of receiving and connecting modules. Through similar collocation of images of divinatory symbols, three black plastic cuboids make up one group, which are placed in a silver drawing hard disk box to form a mobile hard disk as a whole. The light source on each module is yellow to correspond to the color of Taoism culture. The volume of cuboid which represents Yang divinatory symbols is $2 \mathrm{~T}$, while the volume of cuboid which represents Yin divinatory symbols is 1T. The design inspiration originates from evolution of images of divinatory symbols. In different combinations, different volumes of hard disks can be formed according to preferences. Through the application of modern materials, it meets the modern people's aesthetic, both expresses the Taoism culture and achieves the combination of artistry and practicability, and brings fun in the different combination processes of hard disk.

Combine what can be combined with modern life of Taoistic textures with modern goods, combine digital products with traditional cultural elements, not only look good but also are interesting, and have effects on the popularize good culture.
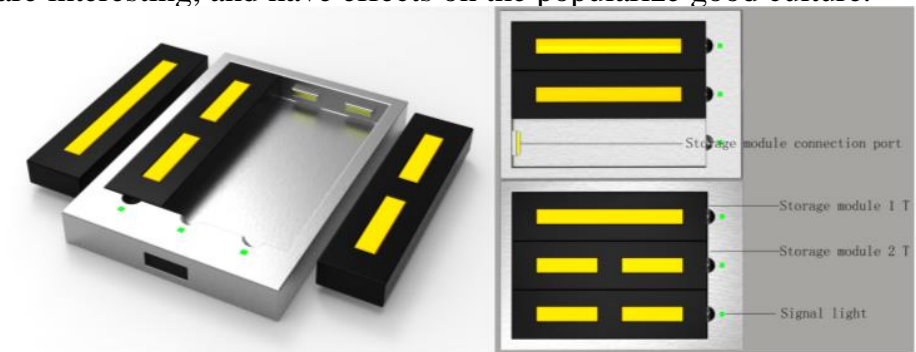

Fig. 3. The Eight Trigrams Mobile Hard Disk Drive 


\section{B. Taoistic Culture - Bamboo cultural and Creative Product} Design

"To say other things before saying what is the theme; to compare the theme to other things; to say other things first to lead to the theme." These are the words by Zhu Xi of Song Dynasty [8]. To express the abstract Taoistic culture through concrete object, especially the rich cultural significance in Taoism world and its symbol, the way can inspire our cultural and creative product design. In the Taoism philosophical world, bamboo is the carrier and concrete symbol of "Tao". In the philosophical view of Taoism, "Bamboo" exists as a materialized symbol and symbol carrier of "Tao". Lao $\mathrm{Zi}$ reveals the essential concept of Taoism on the structure of life and the form of motion in the universe: the middle is virtual, round and flexible. It means that the inner structure of the living body must be hollow, virtual and flexible. Thus, the basic element of life - Qi, can pass through it, thus keeping life alive [9]. The group takes bamboo as Taoistic culture representative and designs a set of audio equipment which has bamboo and bamboo shoot as prototypes (Figure 4). The top of it can give out light therefore creates a sense of mystery and holiness. The metal plate on the middle of the top can be leave as it is, or the guests can choose the words and images they like to print on it. The outside is made of natural bamboo and plain color audio grille to fit the "plain, simple and elegant" notion in Taoism. The "bamboo shoot" is the control swift, and the light goes up and down according to the sound volume. The power source swift is made of metal. As the equipment needs to make sounds through air, there is a hollow space in it. Together with the bamboo-like appearance, the audio equipment fits Taoistic notions well.

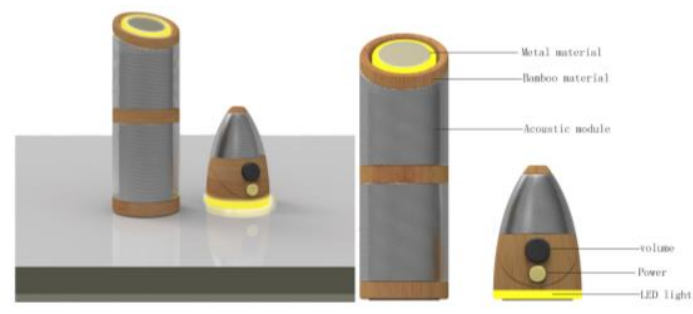

Fig. 4. Bamboo Audio Equipment Design

\section{The Special Architectures in Changchun Taoistic Abbey and Modern Cultural and Creative Product Design}

Except for the classical eight trigrams, there are also some Taoistic architecture with their own characteristics after mixing and developing in history, such as Daozang Building and Huixian Bridge (Figure5). They have seen the development process of Changchun Taoistic Abbey Taoism. Combining these classical items in Taoism with modern cultural and creative products in a signifying and simplifying way can enrich the varies of cultural and creative products of Changchun Taoistic Abbey, increase the Taoistic connotation of the products and let people learn more about Taoism of Changchun Taoistic Abbey.

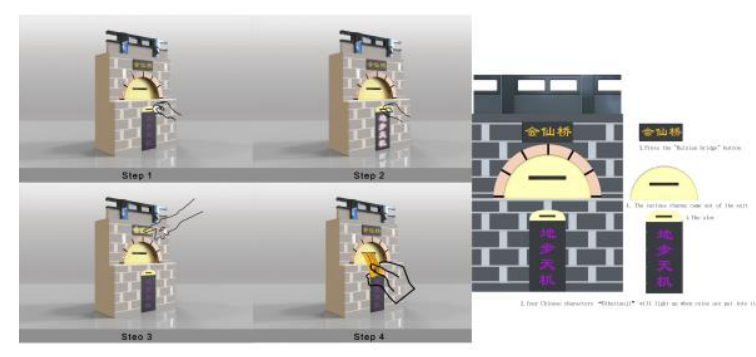

Fig. 5. The Design of Huixian Bridge Saving Pot

In daily life, people often need to seek immortals and worship Buddha, such as exams and promotions. This phenomenon does not disappear with the development of modern life, but often plays a psychological suggestion, let's people through their own efforts to achieve the goals at the same time, and can also play a role in encouraging. We think the Fairy Bridge landscape possesses the function of promising on the spot, which influences people through invisible factors. As a result, the team designed a fun Piggy Bank, and placed it on the desktop as a saving pot to use. The specific steps are: When the coins are put in, a few words of "earth step and heaven opportunity" will brighten and the coins like fall into the mysterious realm. Then the button of "Fairy Bridge" can be presses, various types of charms will randomly appear from the aperture of bridge, which let people have a feeling of wishing. In the process of saving money, it is full of sense of ceremony and interest, while the appearance is primary color of stone material. This design has the basic function of the saving pot, as well as increases the connection with Taoism culture and gives people different feelings through the process of "seeking God". Completing the entire process of wishing through a series of operations is also an imitation of seeking God process. It's also an attempt to connect high tech with high emotions.

\section{CONCLUSION}

We can see the application of eight trigrams texture, bamboo culture and psychological suggestion when honoring the gods in the cultural and creative products designed on the basis of Taoistic culture of Changchun Taoistic Abbey. The cultural and creative products in the plans of the table can combine the adaption to modern life and Taoistic culture at a fine balance. When it comes to the choices of traditional cultural elements, we should obey the principles that adapt to the times and having positive significance. Finding out the suitable things in modern life which can adapt to the derived Taoism make the culture endures and develops in modern society.

The article re-explores and re-utilizes the Taoistic cultural elements of Changchun Taoistic Abbey in ways of the cultural and creative products design and study, make Taoistic cultural accumulation more concrete which is beneficial for the diversification of Changchun Taoistic Abbey and even Wuhan figure and the promotion of culture soft power. The Taoism series cultural and creative products still have many parts remaining to be explored, we hope that the scholars can continue to improve the works and enrich the products and then improve the national culture soft power. 


\section{REFERENCES}

[1] Mei, Mei. Culture Products Facing Teaching Living Lab Creative Design Methods, Decoration, 2013, 9.

[2] Editorial Office of the Journal Chinese Religions. A Clear Field of Jiangchu Where Taoists Gathers - About Changchun Taoistic Abbey Wuhan, Chinese Religions, 2013, 7.

[3] Qing, Xitai. The Position of Taoism in Traditional Chinese Culture and Its Modern Value, Journal of Hunan University, Social Science Edition, Volume 20, 4. 2006.7.

[4] Qing, Xitai. History of Chinese Taoism Volume 1, Sichuan Renmin Press, 1992:146
[5] Ding, Changyun. The Creative Developing Way of Taoism, Chinese Religions, 2017, 3, p48.

[6] Sun, Shuying. Experiencing the Creative Design of Tourism Product, Chinese Market, 2011, 6, pp.102 - 103.

[7] Chen, Shouze. Liu, Xuming. The Study on Cultural Product Marketing, Economic Daily News, Beijing. 2012.

[8] Zhu, Xi. Collection of Poems, Volume 1 Commentary.

[9] Cai, Linbo. Yang, Rong. Hollow and Flexible The Bamboo Culture in Taoism, Chinese Religions, 2013, 7. p44. 